\title{
Karakteristik Perjalanan Armada Barang Minimarket di Kota Makassar
}

\author{
Indriaty Wulansari \\ Program Studi Teknik Sipil, FT UAJ-Makassar \\ E-mail: indriaty.wulansari@gmail.com
}

Received 13 Maret 2020; Reviewed 16 Maret 2020; Accepted 29 Mei 2020

Journal Homepage: http://jurnal.borneo.ac.id/index.php/borneoengineering

DOI: https://doi.org/10.35334/be.v4i1.1306

\begin{abstract}
The growth of minimarkets in Makassar city shows very large numbers. The large growth of outlets is in line with the increase in freight transportation (fleet) that will distribute goods. The storage of minimarkets (Alfamart, Alfamidi, and Indomart) is located in the Makassar Industrial Area (KIMA). This research is descriptive-quantitative. The purpose of this study was to determine the characteristics of the transportation of goods for each type of minimarket. The result showed that the departure time for all types of minimarkets was the same between 07.00-18.00 WITA, then the average speed of the fleet range from $35-45 \mathrm{~km} / \mathrm{hour}$, and the route is chosen was dominantly toll of the total trips.
\end{abstract}

Keywords: Characteristics, Travel, Fleet, Minimarket

\begin{abstract}
Abstrak
Pertumbuhan minimarket di kota Makassar memperlihatkan angka sangat besar. Besarnya pertumbuhan gerai sejalan dengan bertambahnya angkutan barang (armada) yang akan melakukan distribusi barang. Gudang penyimpanan barang minimarket (Alfamart, Alfamidi dan Indomart) berada dikawasan Industri Makassar (KIMA). Penelitian ini bersifat deskriptif kuantitatif. Tujuan penelitian ini adalah untuk mengetahui karakteristik perjalanan angkutan barang tiap jenis minimarket. Hasil penelitian menunjukkan bahwa waktu berangkat untuk semua jenis minimarket adalah sama antara pukul 07.00-18.00 WITA, kecepatan rata-rata armada berkisar 35-45 km/jam dan rute yang dipilih dominan Tol (67\%) dari total perjalanan.
\end{abstract}

Kata kunci: Karakteristik, Perjalanan, Armada, Minimarket

\section{Pendahuluan}

Strategi pembangunan regional yang akan menggunakan daya tarik daerah industri baru, harus dapat menjamin ketersediaan infrastruktur transportasi regional yang memadai untuk industri tersebut (Mahmudah, 2011). Rencana Induk Percepatan dan Perluasan Pembangunan Ekonomi Indonesia (MP3EI) merupakan kebijakan pemerintah dalam menggalakkan persaingan di sektor industri. Kebijakan ini bertujuan untuk mengakselerasi proses transformasi ekonomi nasional ke arah industri berbasis sumber daya alam untuk di daerah luar jawa dan industri teknologi tinggi 
untuk daerah-daerah di pulau jawa (Hakzah, 2016). Meski demikian, secara umum masih banyak hal yang harus dibenahi di setiap koridor ekonomi.

Dukungan peningkatan konektivitas (infrastructure) berupa perbaikan akses jalan guna mengurangi ketergantungan kepada pihak perantara dagang, revitalisasi dan peningkatan kapasitas gudang penyimpanan barang bukan hanya tugas pemerintah dan swasta namun seluruh masyarakat Sulawesi pada khususnya dan masyarakat Indonesia pada umumnya. Berdasarkan kajian IndII (2012) dalam Mulyono (2016), bahwa rata-rata waktu tempuh angkutan barang pada jalan nasional mencapai 2,78 jam/100 km, yang jauh di bawah Vietnam $(2,0 \mathrm{jam} / 100 \mathrm{~km})$, Thailand $(1,3 \mathrm{jam} / 100$ $\mathrm{km})$, Cina $(1,2 \mathrm{jam} / 100 \mathrm{~km})$ dan Malaysia $(1,1 \mathrm{jam} / 100 \mathrm{~km})$.

Transportasi barang yang menggunakan jalan masih sangat dominan baik di negara maju maupun di negara berkembang seperti Indonesia. Investasi double track kereta api dan pengembangan kepelabuhanan belum mendapat respon signifikan bagi operator angkutan barang karena buruknya keterpaduan jaringan prasarana dan pelayanan terminal alih moda transportasi barang (Mulyono, 2017). Beban publik yang ditimbulkan akibat kegiatan pengangkutan barang adalah beban polusi dan beban kecelakaan dikarenakan semakin tinggi kepadatan dijalan raya (Prasetyo dkk, 2013). Jaringan transportasi dapat disusun secara sederhana yaitu menghubungkan pusat besar dengan pusat-pusat sedang, selanjutnya antara pusat sedang dengan pusat-pusat kecil. Pola transportasi semacam ini disebut conventional tree pattern (Adisasmita, 2011).

Dalam meningkatkan kinerja atau aktivitas dari sebuah industri perdagangan, maka strategi perlu di desain untuk mencapai pertumbuhan yang baik dalam hal penjualan, aset, profit atau kombinasi dari keduanya. Hal ini dapat dicapai dengan beberapa cara antara lain penurunan harga, pengembangan produk baru, peningkatan akses pasar yang luas dan mudah di jangkau serta meningkatkan mutu pelayanan (Wibowo dkk, 2015). Menurut Spiro Kostof (1991) dalam Dishub Kota Makassar (2014), faktor-faktor pembentuk struktur kota adalah sebagi berikut:

1. Pola jaringan transportasi

2. Distribusi distrik hunian

3. Pusat - pusat kegiatan aktifitas (nodes)

4. Paradigma perencanaan yang bekerja pada saat itu.

Pusat perdagangan merupakan salah satu kegiatan yang dapat menimbulkan bangkitan pergerakan yang besar, baik itu pergerakan barang maupun orang. Pergerakan ini pastilah mempengaruhi peningkatan volume lalu lintas perkotaan.

Menurut Gunawan (2015), Setiap tahapan proses distribusi barang mulai dari produsen sampai ke konsumen akhir akan memerlukan suatu sistem transportasi (pengangkutan) dalam bentuk sarana maupun prasarana. Adapun karakteristik dari setiap komponen dalam sistem penyaluran barang antara lain : 1) Pengumpul bahan baku, 2) Produsen, 3) Pedagang pengecer/ distributor, 4) Konsumen akhir.

Karakteristik fisik dari barang yang berpengaruh terhadap biaya angkutan dipengaruhi oleh faktorfaktor antara lain volume dan berat barang, kecenderungan rusak, kecenderungan meledak, mudah hilang, kesulitan/kemudahan dalam bongkar muat, kemudahan untuk disimpan, kelebihan panjang, kelebihan berat, kondisi perdagangan, nilai pelayanan, persaingan antar komoditas yang akan diangkut, jarak asal ke tempat tujuan, frekuensi angkutan, jenis moda yang diperlukan.

Biaya perjalanan pada jaringan infrastruktur angkutan barang sangat bervariatif, hal ini mengindikasikan adanya sensitifitas yang tinggi pada sistem angkutan barang terhadap biaya perjalanan (Hakzah dkk, 2016). 
Menurut Dishub Kota Makassar (2014), Dalam menganalisis transportasi barang perlu mempertimbangkan beberapa hal yang khas menyangkut transportasi barang sebagai berikut :

a. Kegiatan transportasi barang di pengaruhi oleh lokasi bahan mentah, pusat produksi (perusahaan-perusahaan) dan pasar/perdagangan.

b. Jumlah komoditi yang sangat beragam, sehingga segmentasi transportasi barang lebih sulit di banding transportasi penumpang.

c. Variasi fisik dari komoditi yang sangat beragam sehingga memerlukan jenis pengangkut yang beragam pula.

d. Tarif/ongkos yang dapat disesuaikan atas dasar negosiasi sehingga sulit untuk memperoleh data yang handal tentang ongkos transportasi barang.

e. Transportasi dipengaruhi oleh faktor operasi seperti ukuran perusahaan, kebijaksanaan distribusi, penyebaran geografis.

f. Faktor geografis yang berpengaruh seperti lokasi dan kepadatan populasi sebagai konsumen.

g. Faktor-faktor dinamis seperti variasi musiman dalam permintaan dan perubahan selera konsumen.

\section{Metode Penelitian}

Dari aspek pembangunan dan infrastruktur, Kota Makassar termasuk salah satu kota Metropolitan di Indonesia, yaitu kota terbesar di luar pulau Jawa setelah kota Medan (Wikipedia, 2017). Luas wilayah kota Makassar tercatat $175.77 \mathrm{~km}$ persegi dengan 14 kecamatan dan 143 kelurahan, memiliki jumlah penduduk sebanyak 1.469.601 juta jiwa (BPS Kota Makassar, 2016).

\subsection{Lokasi dan Rancangan Penelitian}

Lokasi penelitian adalah di kota Makassar yang merupakan ibukota Provinsi Sulawesi Selatan yang terletak antara 11924'17'38' bujur timur dan 508'6'19" lintang selatan. Letak gudang minimarket berada dalam kawasan KIMA (Kawasan Industri Makassar) di jalan Perintis Kemerdekaan km 15. Adapun titik lokasi distribusi barang tiap gerai minimarket (Alfamart, Indomart dan Alfamidi) yang di tinjau adalah gerai-gerai yang berada di 14 kecamatan.

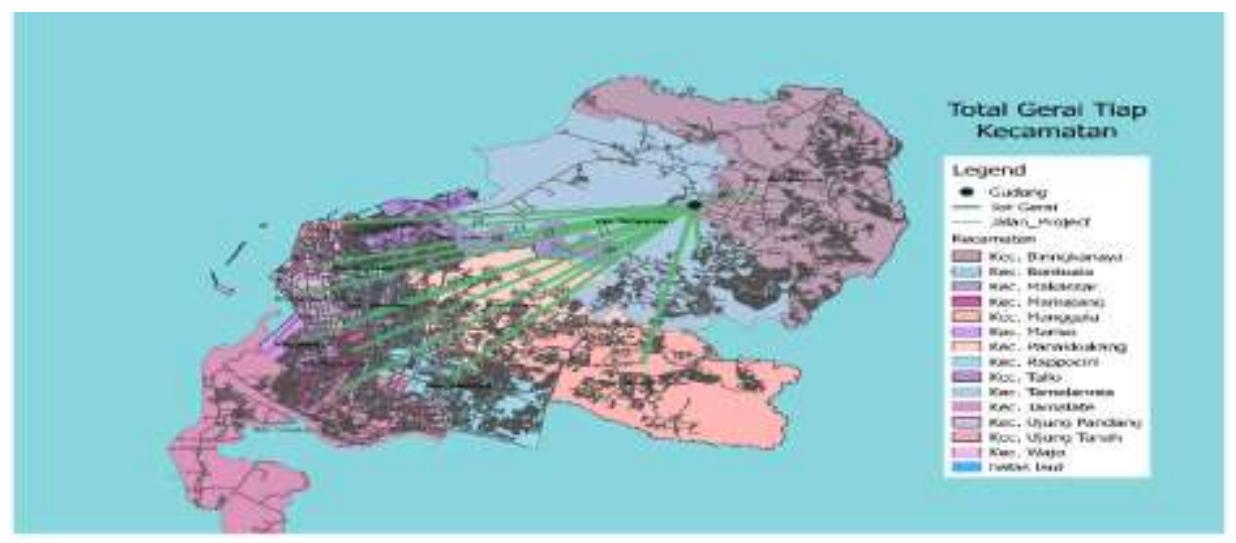

Gambar 1. Lokasi Gerai minimarket

\subsection{Populasi dan sampel}

Berdasarkan data Disperindag (2018), bahwa jumlah minimarket (Alfamart, Alfamidi, Indomart) di kota Makassar berjumlah 487 (legal dan ilegal) unit gerai dan pastinya akan bertambah setiap 
tahunnya. Jumlah sampel yang akan diteliti adalah perjalanan armada barang minimarket pada 78 minimarket (Alfamart, Alfamidi dan Indomart) dalam 14 kecamatan.

\subsection{Metode Pengumpulan Data}

Data yang di ambil adalah data perjalanan armada barang pada minimarket yang tersebar merata di 14 Kecamatan yaitu Kecamatan Biringkanaya, Kecamatan Tamalanrea, Kecamatan Tallo, Kecamatan Panakkukang, Kecamatan Manggala, Kecamatan Rappocini, Kecamatan Tamalate, Kecamatan Mariso, Kecamatan Mamajang, Kecamatan Makassar, Kecamatan Ujung Pandang, Kecamatan Wajo, Kecamatan Bontoala dan Kecamatan Ujung Tanah. Kami mengambil sampel 2 gerai tiap kecamatan dalam 2 hari pada 3 jenis minimarket, sehingga terdapat 78 data perjalanan armada barang (Alfamart, Alfamidi dan Indomart).

\subsection{Analisis Data}

Data pertumbuhan Minimarket di kota Makassar akan dianalisis menggunakan spreadsheet excel. Data di uraikan/dipaparkan menggunakan analisis deskriptif. Secara umum, metode ini terdiri dari dua bagian. Bagian pertama adalah studi literatur yang berhubungan dengan industri ritel (minimarket). Bagian kedua adalah memaparkan hasil analisis kedalam gambar dan tabel. Data yang digunakan adalah data primer yang diperoleh dari survei minimarket di kota Makassar tahun 2018 kemudian tahap selanjutnya dapat dilihat gambaran dalam suatu sistem informasi yang memadukan antara data geografis (spasial) dengan data teks (atribut) yang disajikan dalam desire line pada software Qgis.

\section{Hasil dan Pembahasan}

Karakteristik perjalanan yang akan dibahas pada bagian ini adalah

a. Waktu berangkat merupakan hal yang sangat penting dalam pendistribusian barang dikarenakan kondisi lalu lintas di dalam kota sangat syarat akan kemacetan, sehingga diperlukan management waktu yang tepat agar barang bisa didistribusikan dengan cepat dan efisien dari sisi waktu sehingga biaya bisa di tekan. Adapun waktu pendistribusian barang ke gerai-gerai adalah sama di tiap jenis minimarket. Waktu berangkat dimulai dari pukul 07.00 18.00 WITA untuk pendistribusian barang dalam kota, namun terkadang pendistribusian juga dilakukan di malam hari. Tiap minimarket dominan memilih pendistribusian di pagi hari dibanding sore hari. Distribusi barang dalam kota lebih banyak di pagi hari, dikarenakan kendaran tersebut bisa digunakan pada sore dan malam untuk distribusi barang keluar kota. Untuk distribusi pada Kecamatan Biringkanaya dan Tamalanrea, sering di waktu siang sampai sore hari dikarenakan letaknya lebih dekat dengan kawasan gudang sehingga lebih mudah dalam distribusi.

b. Kecepatan rata-rata pengemudi didalam kota standar menggunakan kecepatan $35-45$ $\mathrm{km} / \mathrm{jam}$. Hampir semua operator mengungkapkan hal yang sama. Meski demikian, ada juga beberapa yang menggunakan kecepatan $50 \mathrm{~km} / \mathrm{jam}$ jika melewati jalan tol dan pendistribusian di pagi hari.

c. Rute dalam kota dari lokasi gudang di Kima untuk mencapai tujuan memiliki 2 pilihan, yakni melalui Tol atau melalui jalan poros (arteri). Gambaran mengenai rute perjalanan armada barang minimarket disajikan pada Gambar 2 dan Gambar 3 


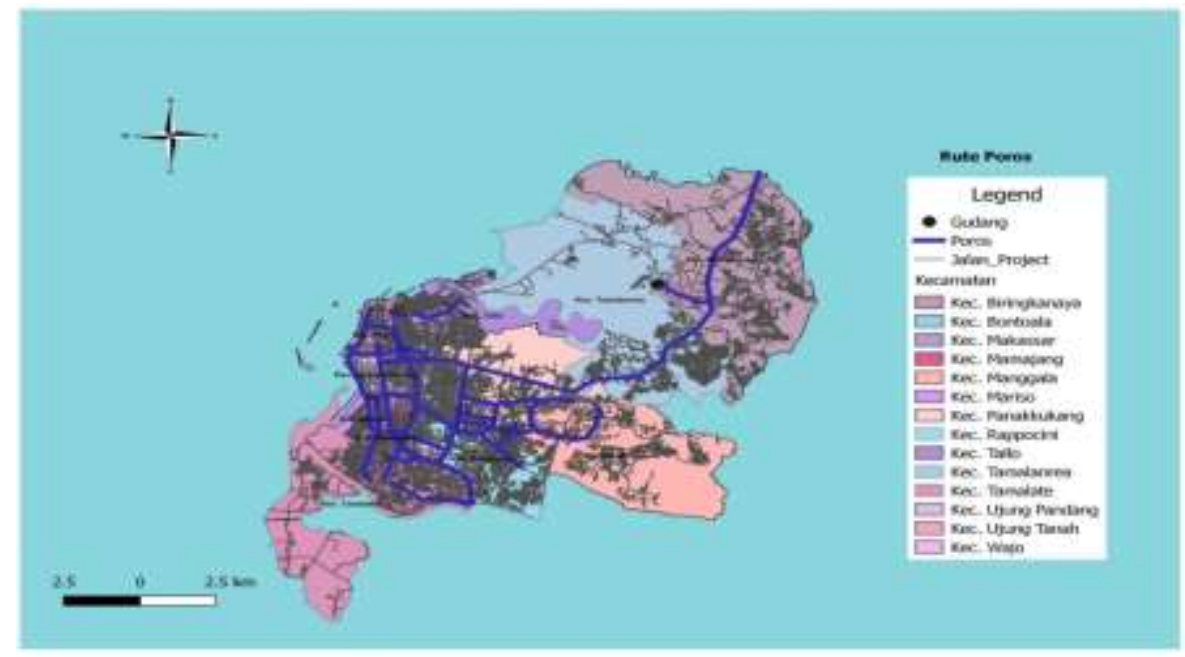

Gambar 2. Rute Distribusi Melalui Poros

Gambar 2 memperlihatkan rute perjalanan armada barang dalam mendistribusikan barang melalui rute poros. Rute ini merupakan rute altenatif yang digunakan operator dalam mendistribusikan barang dalam kota Makassar.

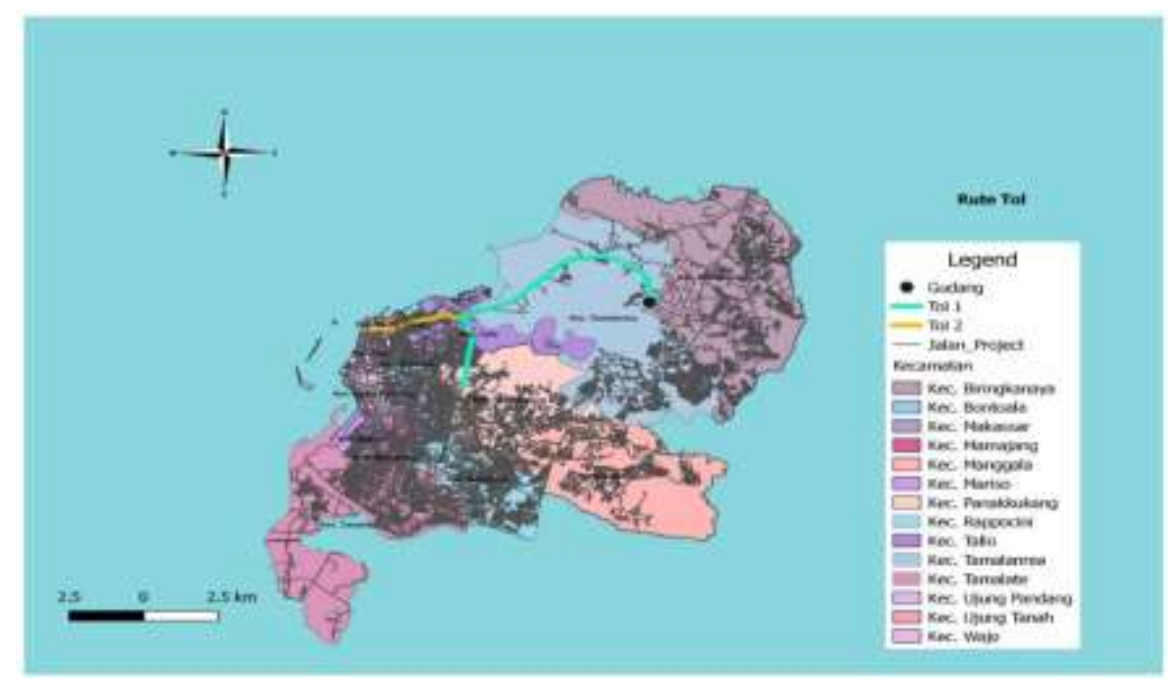

Gambar 3. Rute Distribusi Melalui Tol

Gambar 3 memperlihatkan rute perjalanan armada barang dalam mendistribusikan barang melalui rute tol. Rute ini merupakan rute altenatif yang digunakan operator dalam mendistribusikan barang dalam kota Makassar. Dari hasil survey yang telah dilakukan pada 78 perjalanan armada barang menuju 78 gerai minimarket (Alfamart, Alfamidi dan Indomart) dalam kota Makassar, maka didapatkan hasil seperti Tabel 1 
Tabel 1 Rute Perjalanan Armada Barang Minimarket

\begin{tabular}{cccc}
\hline \multirow{2}{*}{ Kecamatan } & \multicolumn{3}{c}{ Rute yang dilalui } \\
\cline { 2 - 4 } & Alfamart & Alfamidi & Indomart \\
\hline Mariso & Tol & Tol & Tol \\
Mamajang & Tol & Tol & Tol \\
Tamalate & Tol & Tol & Poros \\
Rappocini & Tol & Tol & Poros \\
Makassar & Tol & Tol & Tol \\
U. Pandang & Tol & - & Tol \\
Wajo & Tol & - & Tol \\
Bontoala & Tol & - & Tol \\
U. Tanah & Tol & Tol & Tol \\
Tallo & Tol & Tol & Tol \\
Panakkukang & Poros & Poros & Poros \\
Manggala & Poros & Poros & Poros \\
Biringkanaya & Poros & Poros & Poros \\
Tamalanrea & Poros & Poros & Poros \\
\hline
\end{tabular}

Dari tabel 1 diatas, berikut persentase perjalanan armada barang minimarket (Alfamart, Alfamidi dan Indomart) dalam mendistribusikan barang dalam kota Makassar disajikan dalam Gambar 4

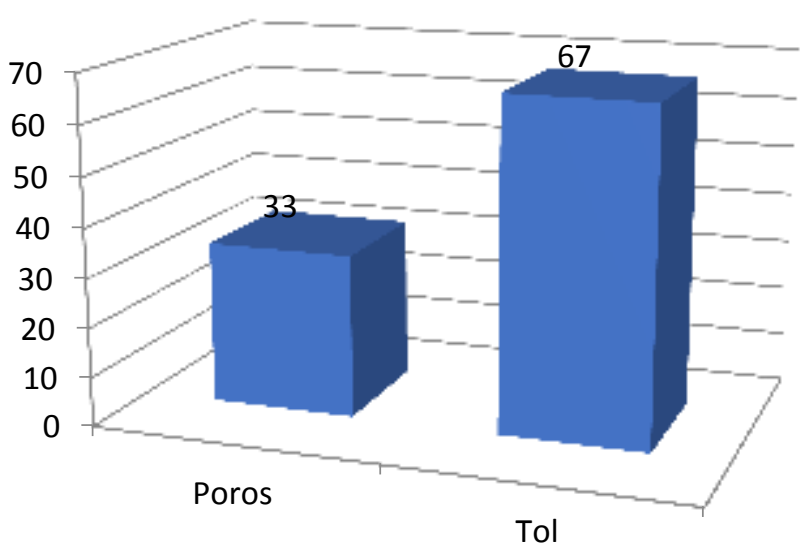

Gambar 4. Persentase Rute Perjalanan Armada Barang Dalam Distribusi Barang

Dari Gambar 4 diatas, dapat dilihat bahwa pemilihan rute tol adalah yang paling dominan. Letak gudang merupakan salah satu factor pemilihan rute tol menjadi dominan dikarenakan akses gudang dengan tol sangat dekat.

\section{Kesimpulan}

Waktu berangkat dalam pendistribusian barang dimulai pada pagi hari untuk distribusi dalam kota, namun terkadang pendistribusian juga dilakukan di malam hari. Kecepatan rata-rata pengemudi 
didalam kota menggunakan kecepatan rata-rata. Meski demikian, ada juga beberapa yang menggunakan kecepatan diatas rata-rata jika melewati jalan tol dan pendistribusian di pagi hari. Dikarenakan letak/posisi gudang yang berada di kawasan industri (KIMA) yang sangat dekat dengan jalur tol, sehingga rute tol paling dominan digunakan oleh operator. rute ini sangat efisien menjangkau semua gerai yang ada di dalam kota Makassar.

\section{Ucapan Terima Kasih}

Kami mengucapkan terima kasih kepada pihak yang telah membantu pada saat survey dilapangan, baik itu mahasiswa maupun pihak terkait penelitian kami sehingga data yang kami butuhkan dapat terkumpul guna mendapatkan hasil yang optimal.

\section{Daftar Pustaka}

Adisasmita, S.A. 2011. Jaringan Transportasi. Graha Ilmu. Yogyakarta.

BPS. 2016. Makassar Dalam Angka. Makassar.

Dishub Kota Makassar. 2014. Pola Pergerakan Angkutan Barang Kota Makassar.

Gunawan,H. 2015. Pengantar Transportasi dan Logistik. RajaGrafindo Persada. Jakarta

Hakzah.,Samang.L.,Djamaluddin,R. \& Ramli,M.I. 2016. A Study on Behaviours of Inter-City Freight Transport Within Province (A Case Study: The Freight Transport in South Sulawesi Province). International Journal of Current Research (IJCR) Vol 8.

Mahmudah,N., Parikesit,D., Malkhamh,S. \& Priyanto,S. 2011. Pengembangan Metodologi Perencanaan Transportasi Barang Regional. Jurnal Transportasi Vol II No 3. Desember 2011:173-182.

Mulyono,A.T. 2016. Ketimpangan Produksi Angkutan Barang dan Penumpang Tiap Moda Transportasi Jalur Utama Pantura Jawa. Jurnal HPJI Vol.2 No 2 Juli 2016:71-78

Mulyono,A.T. 2017. Penyakit Kronis Penyelenggaraan Transportasi Nasional. Makalah disajikan dalam seminar Penyusunan Naskah Akademik Sistem Transportasi Nasional (Sistranas): Pengembangan Sarana-Prasarana Transportasi Kedepan Dalam Perspektif Sistranas. Kampus Teknik Unhas. Makassar 9 Agustus 2017.

Prasetyo E.A. \& Hadi F. 2013. Analisis Pemindahan Moda Angkutan Barang Di Jalan Raya Pantura Pulau Jawa (studi kasus : koridor Surabaya - Jakarta). Jurnal Teknik Pomits Vol 2 No 1. ISSN : 2337-3539.

Wibowo,F.P dan Pahruddin,C. 2015. Strategi Persaingan Usaha angkutan Barang PT. Kereta Logistik. Jurnal Manajemen Bisnis Transportasi Dan Logistik. Vol 1 No 3 Mei 2015.

Wikipedia. 2017. Kota Makassar. Makassar. http://id.wikipedia.org/wiki/Kota_Makassar. 